\title{
Measurement Campaign on Transmit Delay Diversity for Mobile DVB-T/H Systems
}

\author{
R. Di Bari, M. Bard, A. Arrinda, P. Ditto, J. Cosmas, K.K. Loo, and R. Nilavalan
}

\begin{abstract}
This paper describes the work carried out by Brunel University and Broadreach Systems (UK) to quantify the advantages that can be achieved if Transmit Delay Diversity is applied to systems employing the DVB standard. The techniques investigated can be applied to standard receiver equipment without modification. An extensive and carefully planned field trial was performed during the winter of 2007/2008 in Uxbridge (UK) to validate predictions from theoretical modeling and laboratory simulations. The transmissions were performed in the $730 \mathrm{MHz}$ frequency band with a DVB-T/H transmitter and a mean power of $18.4 \mathrm{dBW}$. The impact of the transmit antenna separation and the MPE-FEC was also investigated. It is shown that transmit delay diversity significantly improves the quality of reception in fast fading mobile broadcasting applications.
\end{abstract}

Index Terms - Broadcasting, MISO, Delay diversity (DD), DVB-T/H, Errored Second Ratio (ESR), Field Trials.

\section{INTRODUCTION}

$\mathrm{C}$ urrent broadcast TV networks have been designed to enable reception by rooftop antennas, mainly in Line of Sight (LOS) conditions, while next generation digital TV service providers for mobile and fixed reception are finding that coverage indoors and areas of Non Line Of Sight (NLOS) is a fundamental requirement. It is essential that such networks are designed cost-effectively and with minimized environmental impact. Multipath can result in severe fading in Non Line of Sight reception situations. A radio network design must take this into account when predicting service availability. Traditionally broadcast reception in multipath situations is provided by increasing the density of transmitters and/or increasing the radiated power.

The use of transmit diversity techniques with multiple antennas have long been proposed to improve the performance and capacity of wireless systems [2][3]. Multiple Input Multiple Output (MIMO) systems use several antennas for

Manuscript received November 9, 2008. This work was supported in part by the EU FP6 PLUTO Project.

R. Di Bari, J. Cosmas, K.K. Loo and R. Nilavalan are with the School of Engineering and Design, Brunel University, Uxbridge, West London, UK (email:raffaele.dibari,John.Cosmas,Jonathan.Loo,Rajagopal.Nilavalan@brunel.a c.uk).

Maurice Bard is with Broadreach System, UK (email: mail@broadreachsystems.com).

A. Arrinda is with Universidad del País Vasco, ES (email: amaia.arrinda@ehu.es )

P. Ditto is with Università degli Studi Mediterranea, IT (email: paolo.ditto@gmail.com ) transmission and reception. Multiple Input Single Output (MISO) systems use several antennas for transmission and just one for reception. In Delay Diversity (DD) transmit systems, the same information is transmitted from both antennas simultaneously but with a delay to overcome the effects of flat fading by reducing the probability of observing deep fades at the receiver. Spatial transmit diversity can be implemented by transmitting identical signals from different transmit antennas, which are spatially separated from each other. This spatial separation of transmit antennas is required to achieve a sufficient decorrelation of the channels. Simulations carried out in [4] suggest that a minimum separation of approximately 10 times the carrier frequency wavelength is required for a typical urban transmitter. This antenna separation is typically not enough to decorrelate the channels in LOS or near LOS conditions, resulting in a performance degradation if Delay Diversity is applied. Several methods of overcoming this effect are currently being researched .

Previous published works [5][6] present DVB-T/H software simulations of the DD gain with MIMO uncorrelated channels, while [7] extends the results to MIMO correlated channels. The coverage improvement of DVB-H networks with DD is presented in [8], while [10] and [11] show the impact of this technique on LOS channels. Measurement results deploying a real DVB-T receiver in a laboratory test bench are described in [12][13]. Preliminary results for DVB$\mathrm{T}$ field trials are presented in [14][15]. This paper presents an extensive and carefully planned DVB-T field trial performed from 2007 to the summer of 2008 in Uxbridge (UK). The experiments were also extended to DVB-H to verify generically that any OFDM system can exploit diversity gains predicted by theory. This generic understanding can then be applied to different standards such as DVB-SH, DAB/DMB and MediaFLO. The outline of this paper is as follows. The experimental network deployed for the field tests is described in Section II. The different investigated scenarios for mobile reception are discussed in Section III. Section IV presents the parameters used to analyze the performance. The results for the DVB-T experiment are presented in Section V. Section VI presents the results for DVB-H network. Finally, the conclusions are presented in Section VII.

\section{EXPERIMENTAL NETWORK}

The experimental network is presented in this section. First the transmitter set-up is described, then, the receiver set-up. 
The transmitter and receiver calibration is also detailed.

\section{A. Transmitter}

The transmitter is located at Brunel University in Uxbridge, in the west outskirts of London, $1.2 \mathrm{~km}$ south of Uxbridge. The measurement area is relatively flat and representative of a typical suburban area. The field trial used two power amplifiers, rated at $100 \mathrm{~W}$, feeding a linear array of directive antennas. In the tests quality of reception in the measurement area when either all power was transmitted from a single antenna (Single Input system) or half power from each of two separate antennas (Multiple Input system) was compared. The EIRP measured was $18.4 \mathrm{dBW}$ for both the single transmitter and dual transmitter configurations on channel 53 which has a central frequency of $730 \mathrm{MHz}$ and bandwidth of $8 \mathrm{MHz}$. A linear array of directive antennas was installed at the top of one of the university buildings (named Tower D), pointing towards the east. The antennas are horizontally polarized panels with a gain of $12 \mathrm{~dB}$, a half-power beam-width of $53^{\circ}$ degrees in the $\mathrm{H}$ plane and $24^{\circ}$ degree in the $\mathrm{V}$ plane. The antennas radiation pattern is presented in [16].

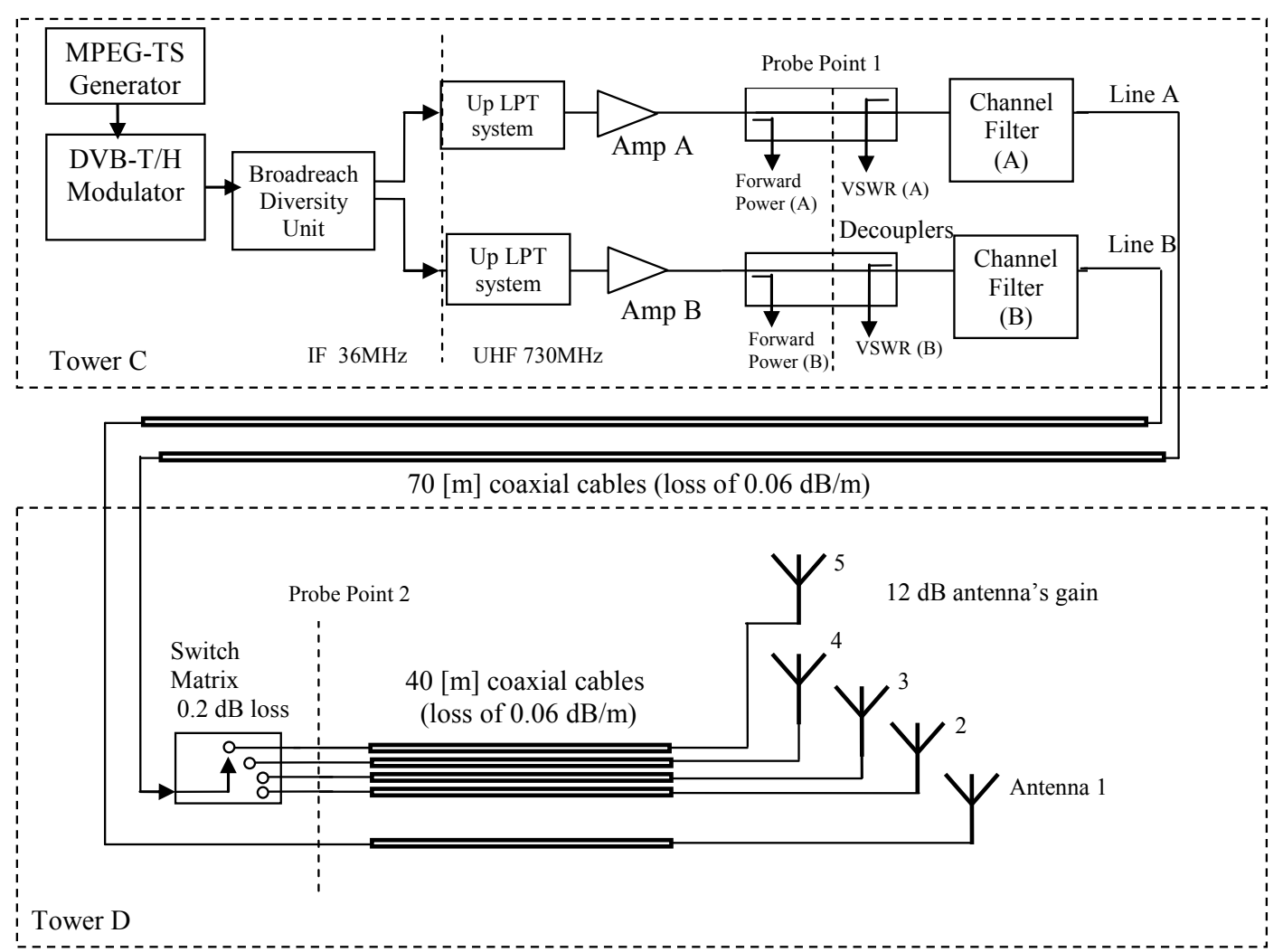

Fig. 2. The RF diversity transmit system

A maximum number of two antennas (out of five) were active at any time. In that way, the horizontal spatial separation between active antennas could be selected from 7 to 20 wavelengths. A vertical separation of 5 wavelengths can be optionally selected. Table I summarizes the main technical characteristics of the transmission system. Fig. 2 shows the schematic of the transmit system. The transport stream comprised Pseudo Random Binary Sequence (PRBS) packets for field measurements; the system is also capable of delivering multimedia content, encoded into MPEG-2 Transport Stream (TS) packets and transmitting it over the network for demonstration purposes.

In case of DVB-H tests, sample video streams described in Section VI were transmitted. A standard DVB-T Modulator was used to feed IF signals directly into the Broadreach Diversity Unit (custom made), introducing a $1.1 \mu$ s relative delay between the two transmitted signals. Previous works based on simulations and laboratory tests proved the highest diversity gain is reached when adopting such a delay value [7] [8]. The Diversity Unit has been designed to aid research into transmit diversity for DVB-T and DVB-H. The unit digitizes the input signal and passes it to a Digital Signal Processor (DSP). This DSP allows the signal to be split into 2, each signal being processed by a number of digital filter stages before being passed to 2 independent upconverter/modulator devices. The low power transmitter (LPT) up converts the signal to $730 \mathrm{MHz}$. The signal is then amplified and filtered. The Amplifier A and Amplifier B have similar performance. The total feeder loss was $6.8 \mathrm{~dB}$ and the switch matrix connecting the amplifier $\mathrm{B}$ with one of the diversity antennas had a loss of $0.2 \mathrm{~dB}$.

MISO tests were carried out using two transmit antennas, out of five. For SISO tests just one transmit antenna is used. 
TABLE I

TECHNICAL CHARACTERISTICS OF THE TRANSMISSION

\begin{tabular}{lll}
\hline \hline Transmitter Centre & Uxbridge & \\
\hline Broadcaster & Brunel University & \\
Coordinates & $51.532367 \mathrm{~N} ; \quad 0.473218 \mathrm{~W} \quad$ Decimal \\
& Degrees (DD) & \\
Frequency & $730 \mathrm{MHz}$ & \\
Bandwidth & $8 \mathrm{MHz}$ \\
EIRP & $18.4 \mathrm{dBW}$ \\
Antenna & Directive/Horizontal Polarized \\
Antenna(s) gain & $12 \mathrm{~dB}$ \\
Antenna separations & $7 \lambda, 14 \lambda, 20 \lambda$ horizontal or \\
& $20 \lambda$ horizontal and $5 \lambda$ vertical. \\
Total feeders loss & $6.8 \mathrm{~dB}(6.6 \mathrm{~dB}+0.2 \mathrm{~dB})$ \\
Height of the antenna above \\
the ground
\end{tabular}

Signal quality was tested at several stages in the transmit chain to ensure it was acceptable. A typical Modulation Error Rate (MER) of $30.5 \mathrm{~dB}$ was measured with a standard receiver [9] at the output of both amplifiers for both SISO and MISO configurations. The relative levels of the spectrum shoulders are fully compliant with the RF signal spectrum mask of DVB-T standard [17][18]. The two amplifiers did not introduce any significant non-linear effects within the power operational range. The power transfer system was calibrated and the power levels were carefully measured, adjusted and monitored during the measurements using a power measurement device with calibration traceable to national standards [15][17]. In the MISO case each antenna transmitted half of the EIRP of the SISO case. The signal quality at full output power was comparable for both transmitters. A preliminary set of driving measurements presented in [15] was performed on a radial route to test the average received signal strength indication (RSSI), carrier to noise ratio (CNR) and reception quality

\section{B. Receivers}

Mobile reception was measured using a purpose developed DVB-T receiver provided by Broadreach Systems. This receiver allowed measurement of uncorrectable ReedSolomon blocks, Carrier to Noise Ratio (CNR), the Received Signal Strength Indication (RSSI) and delay spread all tagged with a GPS position, time and speed. A single antenna receiver system was used in all cases The equipment was thoroughly calibrated and tested in a simulation laboratory so that its performance compared to theoretical predictions was understood [12][19]. From these measurements we would be able to derive the impact of diversity on other OFDM based broadcast standards.

Mobile reception was measured using a car equipped with the Broadreach DVB-T receiver. Fig. 3 illustrates the integrated system used to record seconds in which uncorrectable Reed-Solomon blocks are observed and from whom the Errored Second Ratio (ESR) is calculated. The CNR and RSSI are also measured together with location coordinates acquired using a GPS receiver.

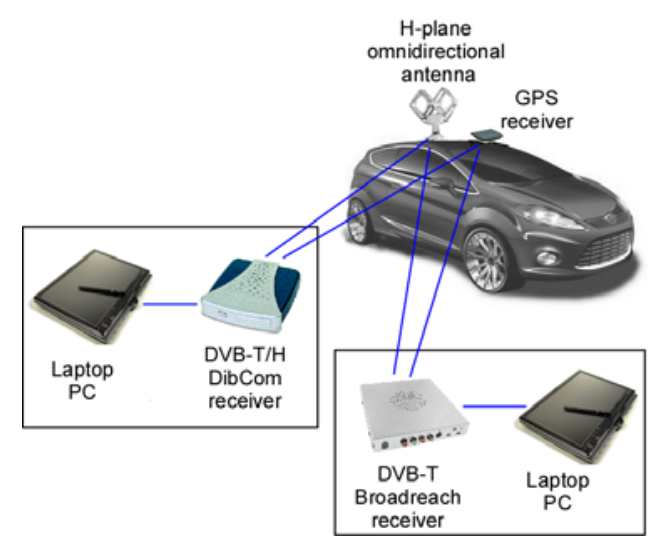

Fig. 3. The car experimental set-up

After the initial measurement campaign using the Broadreach receiver a second campaign was performed using a proprietary DVB-H receiver provided by Dibcom [21]. This campaign enabled us to check that our DVB-T measurements could be correlated with DVB-H performance in accordance with theoretical predictions. A locked DVB-H receiver can receive DVB-H frames, which are either correct or incorrect. Incorrect tables can (sometimes) be corrected by the MultiProtocol Encapsulation Forward Error Correction (MPE-FEC) code. The DVB-H receiver was supplied with a tool which logs parameters such as Carrier to Noise Ratio (CNR), Frame Error Rate (FER), and Multi-Protocol Encapsulation FER (MFER). MFER is the ratio of the number of residual erroneous frames (i.e., not recoverable) and the number of received frames. FER is the ratio of the number of erroneous frames before MPE-FEC correction and the number of received frames [22]. Location and speed are recorded with a GPS device. The signal was received using an omnidirectional horizontally polarized antenna, installed on the rooftop of the test vehicle. The antenna radiation pattern is presented in [16].

\section{AREA CLASSIFICATION AND SELECTION}

Fig. 4 and 5 show the two selected routes which covered mainly suburban zones and included wide and medium roads in all directions reaching marginal areas of Brunel's service coverage. Route A was in the main direction of the transmit power and it is approximately $13.2 \mathrm{~km}$ long. Route B was also in the main direction of the transmit power and it was selected to ensure similar propagation features and a more constant speed during the tests. It should be mentioned that the measurements were repeated two or three times on the same routes. In total more than $500 \mathrm{~km}$ of mobile measurements were recorded. The areas are classified in Table II according to the propagation impairments in ITU-R P1411-4 [26] and previous works [28] [26] [30]. The experiment receiving conditions can be associated to a class $\mathrm{C}$ reception [22]. 


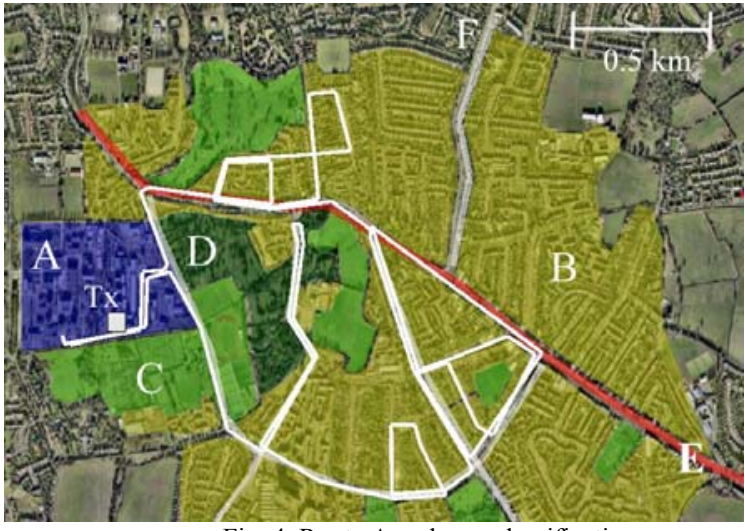

Fig. 4. Route A and area classification

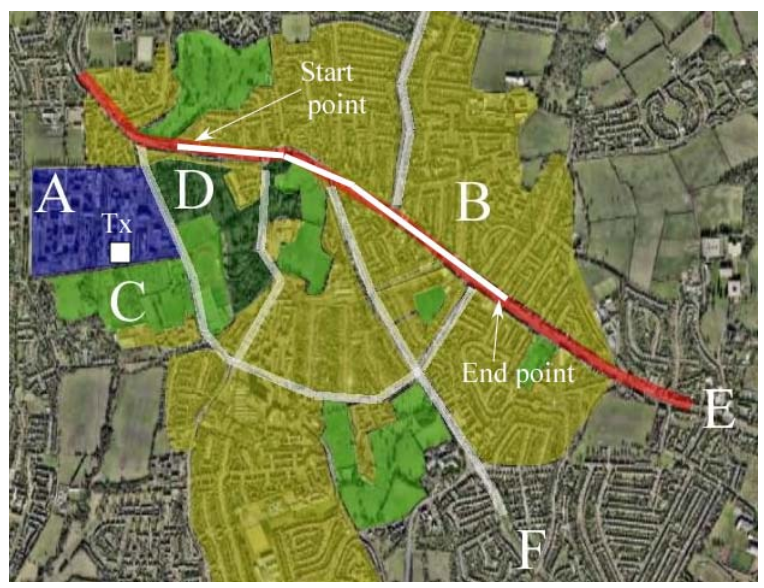

Fig. 5. Route B and area classification

TABLE II

DESCRIPTION OF ZONES

\begin{tabular}{|c|c|c|c|}
\hline Class & Scenario & Zone & Description \\
\hline $\mathrm{C}$ & Car, $20 \mathrm{~km} / \mathrm{h}$ & $\mathrm{A}$ & $\begin{array}{l}\text { High buildings, offices, and } \\
\text { residential halls }\end{array}$ \\
\hline $\mathrm{C}$ & Car, $20 \mathrm{~km} / \mathrm{h}$ & $\mathrm{B}$ & $\begin{array}{l}\text { Low density suburban area, with a } \\
\text { significant presence of trees and } \\
\text { vegetation }\end{array}$ \\
\hline $\mathrm{C}$ & Car, $20 \mathrm{~km} / \mathrm{h}$ & $\mathrm{C}$ & Sport playgrounds \\
\hline $\mathrm{C}$ & Car, $20 \mathrm{~km} / \mathrm{h}$ & $\mathrm{D}$ & Playgrounds with trees \\
\hline $\mathrm{C}$ & Car, $48.2 \mathrm{~km} / \mathrm{h}$ & $\mathrm{E}$ & Roads with two lanes each way \\
\hline $\mathrm{C}$ & Car, $48.2 \mathrm{~km} / \mathrm{h}$ & $\mathrm{F}$ & Roads with one lane each way \\
\hline
\end{tabular}

\section{PARAMETERS USED TO ANALYZE PERFORMANCE}

This section defines the parameters used to analyze the performance of the DVB-T/H systems.

\section{A. DVB-T parameters}

$\mathrm{ESR}_{\%}$ denotes the percentage of the time when seconds are marked as erroneous. An erroneous second consists of a second containing at least one faulty TS-MPEG packet.

$$
E S R_{\%}=\frac{\text { Erroneous Seconds } \times 100}{\text { Number of Measurement Seconds }}
$$

The degradation point is set to $5 \%$ value and it is denoted as $\mathrm{ESR}_{5 \%}[23]$.

\section{B. DVB-H parameters}

FER\% is defined as the ratio between the number of the erroneous frames and the total number of frames. A frame is marked erroneous if any TS packet within the frame is erroneous.

$$
F E R_{\%}=\frac{\text { Number of Erroneous MPE Frames } \times 100}{\text { Total Number of Frames }}
$$

The degradation point is set to $5 \%$ value and it is denoted as $\mathrm{FER}_{5 \%}$

MFER $_{\%}$ is the ratio between the number of erroneous frames after the MPE-FEC correction and the total number of frames.

$M F E R_{\%}=\frac{\text { Number of Erroneous Frames } \times 100}{\text { Total Number of Frames }}$

The degradation point is set to $5 \%$ value and it is denoted as MFER $_{5 \%}$. The performance enhancement due to the diversity for $\mathrm{ESR}_{\%}$ and $\mathrm{FER}_{\%}$ and $\mathrm{MFER}_{\%}$ are referred as $\Delta_{E S R_{\%}}, \Delta_{F E R}$ and $\Delta_{M F E R}$, respectively.

\section{Measurement Results For DVB-T}

This section presents the results of the field trials. First the reception channel features are described. Then, the Diversity Delay performance for DVB-T is evaluated and compared with literature. Finally the results related to antenna separation are presented.

\section{A. DVB-T Tests}

The time required for driving along the route $\mathrm{A}$ was approximately 30 minutes. The diversity gain was estimated by comparing SISO and MISO driving tests performed sequentially to ensure analogous traffic conditions for the two measurements. Weather conditions were sunny or partly cloudy and background traffic was generally light/medium. Typical speeds were in the range of 0 to $48.2 \mathrm{~km} / \mathrm{h}$, with an average of $30 \mathrm{~km} / \mathrm{h}$. The measurements taken when the receiver was stationary were removed from the data presented here to eliminate the effects of random stops due to traffic lights on the total reception statistics. The test results presented here were obtained employing the broadcast conditions described in Table III. A $20 \lambda$ horizontal antenna separation was adopted for the tests because it yielded the highest gain among the possible MISO configurations (as it will be shown in section V.G).

TABLE III

DVB-T SYSTEM PARAMETERS

\begin{tabular}{|c|c|c|}
\hline Configuration Name & SISO & MISO \\
\hline Code Rate & \multicolumn{2}{|c|}{$3 / 4$} \\
\hline Signal Constellation & \multicolumn{2}{|c|}{ QPSK } \\
\hline DVB-T Mode & \multicolumn{2}{|c|}{ Non hierarchical } \\
\hline Hierarchy $(\alpha)$ & \multicolumn{3}{|c|}{$1 / 32$} \\
\hline Guard Interval & \multicolumn{2}{|c|}{9.05} \\
\hline Bitrate (Mbit/s) & 18.4 & 15.4 (ant. 1) +15.4 \\
EIRP (dBW) & - & 20 \\
\hline Antenna separation $(\lambda)$ & - & 1.1 \\
\hline Diversity Delay $(\mu s)$ & \multicolumn{2}{|c|}{} \\
\hline
\end{tabular}




\section{B. Channel estimation and features}

This section describes the methodology and the processing employed to derive the channel features from measurements and a channel model to characterize the propagation scenario. The resulting models represent an outdoor mobile channel for SISO and MISO DVB networks. In [12], the authors show how the transmit DD gain is related to the propagation channel and to its parameters, particularly to the root mean square delay spread (RMS DS). The Broadreach receiver used in this campaign, is capable of capturing channel Impulse Responses (IRs) consisting of 77 sample taps, equally spaced by $74 \mathrm{~ns}$ according to the device specification. The IRs were measured every 1 second and stored in a text log file. In this analysis we have chosen an appropriate power threshold to reduce noise. After studying the measurement data, it was concluded that $30 \mathrm{~dB}$ is an appropriate value for the dynamic range of the impulse responses. This means that signals which are $30 \mathrm{~dB}$ below the strongest power level are considered to be noise. This threshold is also consistent with other published works [24]. Path loss and shadowing effects were removed by normalizing the peak power of each impulse response to $0 \mathrm{~dB}$. For each IR, the tap with maximum power $(0 \mathrm{~dB})$ was chosen as reference starting point and the last tap with power exceeding the $-30 \mathrm{~dB}$ threshold was chosen as last value. Finally, the IRs were averaged yielding an average power delay profile (PDP). A typical number of 1000 IRs are averaged. Three parameters were analyzed from the acquired data: total excess delay, the RMS DS, and the number of taps. The total excess delay by definition is the difference in delay between the first and the last of the received taps. The RMS DS and the excess delay are defined in [20]. The number of taps is considered as the taps within the total excess delay. Table IV shows the average parameters of the SISO and MISO channel models. The second transmitter affects the values of the RMS DS and the number of the taps, by approximately doubling as expected. Moreover, the excess delay is increased to about $1.04 \mu \mathrm{s}$.

TABLE IV

CHANNEL PARAMETERS

\begin{tabular}{lll}
\hline \hline & SISO & MISO \\
\hline $\begin{array}{l}\text { Number of IRs used } \\
\text { in the estimation }\end{array}$ & 998 & 1018 \\
RMS DS (us) & 0.21 & 0.59 \\
Excess Delay (us) & 2.2 & 3.2 \\
Number of taps & 32 & 45 \\
\hline \hline
\end{tabular}

Fig. 6 and 7 show the PDP over the route A for SISO and MISO configuration. The second cluster of echoes generated by the second diversity antenna starts at about $1.1 \mu \mathrm{s}$. It should be noted that the average peak power of the second cluster is very similar to the peak power of the first cluster ( $0.2 \mathrm{~dB}$ below the first cluster peak), providing a qualitative confirmation of the equal average power radiated from the two transmit antennas.

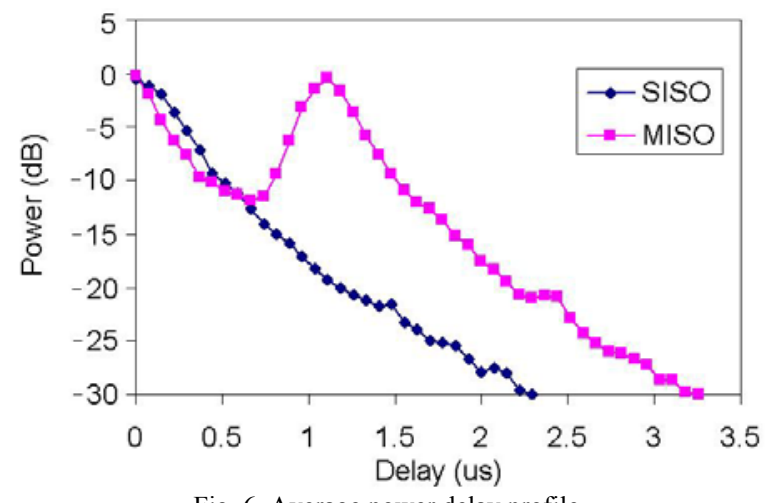

Fig. 6. Average power delay profile

The exact delay and power values of the taps for the SISO and MISO models are given in Table V. The reasons for showing just the first 31 taps were as follows: to unify the two models and to find a compromise between accuracy and complexity of the channel models (both models report taps to at least $-20 \mathrm{~dB}$ ).

TABLE V

SISO AND MISO POWER DELAY PROFILE MODELS

\begin{tabular}{c|c|c|c|c|c}
\hline $\begin{array}{c}\text { Delay } \\
\text { [us] }\end{array}$ & $\begin{array}{c}\text { PDP }(\mathrm{dB}) \\
\text { SISO }\end{array}$ & $\begin{array}{c}\text { PDP (dB) } \\
\text { MISO }\end{array}$ & $\begin{array}{c}\text { Delay } \\
\text { [us }]\end{array}$ & $\begin{array}{c}\text { PDP }(\mathrm{dB}) \\
\text { SISO }\end{array}$ & $\begin{array}{c}\text { PDP (dB) } \\
\text { MISO }\end{array}$ \\
\hline 0 & 0 & 0 & 1.184 & -19.5 & -1.4 \\
0.074 & -0.7 & -1.7 & 1.258 & -20.2 & -3.5 \\
0.148 & -1.4 & -4.2 & 1.332 & -20.7 & -5.6 \\
0.222 & -3.2 & -6.1 & 1.406 & -21.3 & -7.4 \\
0.296 & -4.9 & -7.4 & 1.48 & -21.0 & -9.2 \\
0.37 & -6.7 & -9.5 & 1.554 & -22.8 & -10.7 \\
0.444 & -8.8 & -10.0 & 1.628 & -23.5 & -11.9 \\
0.518 & -9.8 & -10.8 & 1.702 & -24.5 & -12.4 \\
0.592 & -10.7 & -11.1 & 1.776 & -24.7 & -13.5 \\
0.666 & -12.1 & -11.7 & 1.85 & -25.0 & -15.0 \\
0.74 & -13.6 & -11.2 & 1.924 & -26.2 & -15.8 \\
0.814 & -14.5 & -9.2 & 1.998 & -27.4 & -17.4 \\
0.888 & -15.4 & -6.1 & 2.072 & -27.1 & -18.1 \\
0.962 & -16.6 & -3.0 & 2.1 & -27.5 & -19.2 \\
1.036 & -17.8 & -1.3 & 2.22 & -29.1 & -20.55 \\
1.11 & -18.7 & -0.3 & - & - & - \\
\hline \hline
\end{tabular}

Comparisons of the SISO channel model with previous published works show good agreement. The mobile DVB channel profile with single transmitter published in [24] is very close to the PDP shown in Fig. 6 and Table V, while the RMS DS and excess delay, $0.25 \mu \mathrm{s}$ and $2.21 \mu \mathrm{s}$, match well with the SISO channel parameters proposed in Table IV.

\section{Diversity Delay performance over different days}

Fig. 8 shows the $\mathrm{ESR}_{\%}$ for the entire route A for SISO and MISO configuration. The measurements were taken during different days with different traffic and weather conditions. In each case, multiple measurements were conducted during the same day. It was noted that the MISO performances are always better than SISO. 


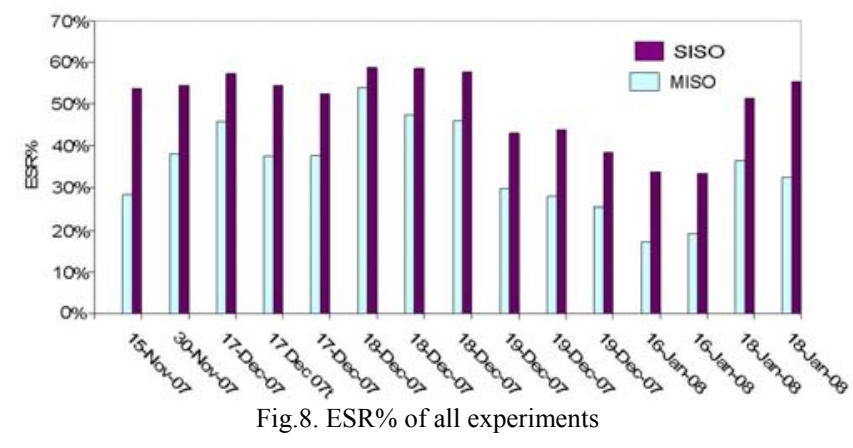

A $95 \%$ confidence interval (CI) derived from Student's tdistribution [25] and referred to the sample mean is estimated in Table VI. The t-student distribution is usually adopted to calculate the confidence interval when the sample size is small. The two SISO and MISO 95\% CI intervals do not overlap, suggesting that there is less than $5 \%$ of possibility for MISO $\mathrm{ESR}_{\%}$ to reach values as high as SISO $\mathrm{ESR}_{\%}$. The $\mathrm{ESR}_{\%}$ values out of the confidence interval are probably due to significant variations of the traffic conditions for the measurements compared. Impulsive noise due to car engine ignition systems also should be considered [22]. The sample mean of $\Delta_{E S R_{\%}}$ is about $14.7 \%$.

TABLE VI

SAMPLE MEAN AND VARIANCE OF THE GAIN MEASUREMENTS AND CONFIDENCE INTERVALS DERIVED FROM STUDENT'S T-DISTRIBUTION

\begin{tabular}{|c|c|c|c|c|c|}
\hline & 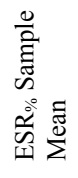 & 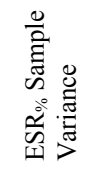 & 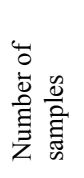 & 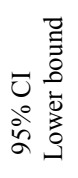 & 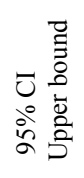 \\
\hline SISO & 48.42 & 81.50 & 23 & 45.19 & 51.65 \\
\hline MISO & 33.71 & 130.15 & 23 & 29.63 & 37.80 \\
\hline
\end{tabular}

\section{D.ESR\% gain estimation}

The $\mathrm{ESR}_{5 \%}$ for different values of RSSI was estimated using all data presented in section $\mathrm{C}$. The RSSI value is provided from the receiver and is computed directly from the automatic gain controls (AGC) outputs. Approximately $2.5 \times 10^{6}$ data measurement seconds are used for the processing. Fig. 10 shows the SISO and MISO ESR $\%$ against the RSSI values. Per each RSSI point, at least 100 seconds are considered to calculate the $\mathrm{ESR}_{\%}$. Each $\mathrm{ESR}_{\%}$ point is calculated taking data from a $3 \mathrm{~dB}$ interval. The curves show a diversity gain at $\mathrm{ESR}_{5 \%}$ of about $4 \mathrm{~dB}$.

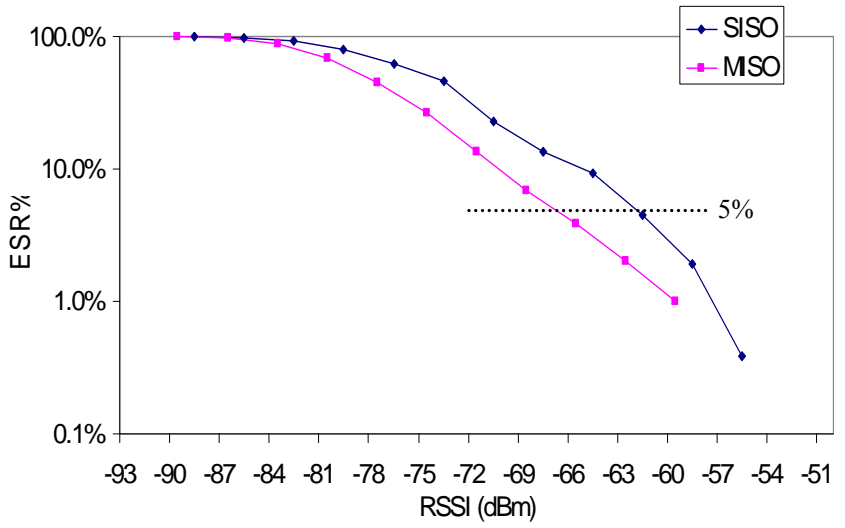

Fig. 10. SISO and MISO ESR\% vs. RSSI

It is possible to compute the SISO and MISO coverage percentage from the same set of data. The $\mathrm{ESR}_{\%}$ shown in Fig. 10 can also be seen as coverage percentages. A similar approach can also be found in [30]. Thus per each value of SISO coverage a corresponding value of MISO coverage can be mapped for the same RSSI. Fig. 11 shows that a coverage of network planning reference $95 \%$ and $70 \%$ (e.g. "good" and "acceptable" reception, respectively) [22] with MISO transmitter corresponds to $88 \%$ and $50 \%$ coverage respectively with SISO.

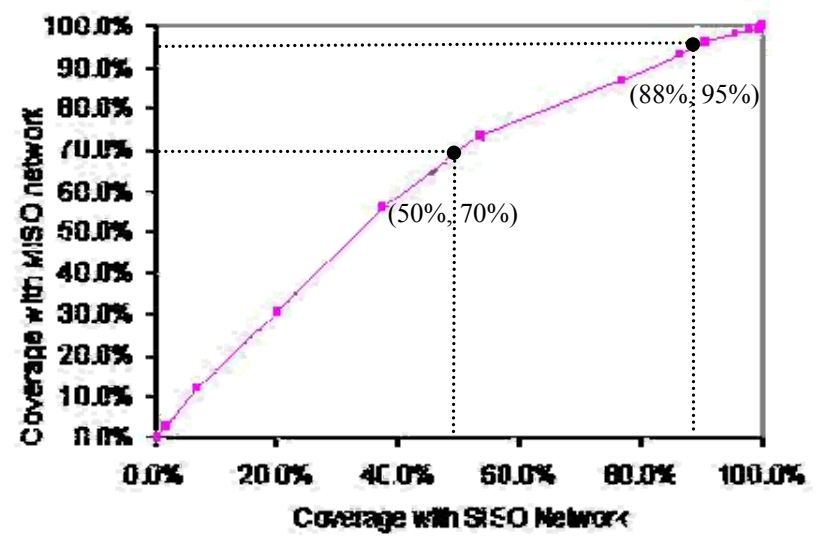

Fig. 11. MISO vs. SISO coverage

\section{E. Capacity improvement estimation}

An additional set of measurements along the route A has also been conducted to explore how transmit diversity might be used to enhance system throughput capability. SISO and MISO ESR $\%$ was compared at 3 different code rates of $1 / 2$, $2 / 3$ and $3 / 4$. The tests were repeated over 4 different days. Table VIII shows the detailed measured ESR $\%$ values. From these measurements the throughput of a SISO network with a code rate $2 / 3$ can be achieved with the same or better reception quality by using a MISO network with a code rate $3 / 4$. [31] shows that at least $2.1 \mathrm{~dB}$ is required to achieve the same $\mathrm{ESR}_{5 \%}$ when the code rate changes from $2 / 3$ to $3 / 4$ in a portable outdoor (PO) channel. The $4 \mathrm{~dB}$ gain estimated at $\mathrm{ESR}_{5 \%}$ in subsection $\mathrm{C}$ ensure that a SFN network can be 
planned for mobile reception using a QPSK 3/4 modulations with MISO set-up and having the same or better reception quality of a standard SISO QPSK 2/3 set-up network, resulting in a throughput improvement of $1 \mathrm{Mbps}$.

TABLE VIII

SISO AND MISO ESR。 WITH DIFFERENT CODES RATES.

\begin{tabular}{ccccccc}
\hline & \multicolumn{3}{c}{ SISO ESR $\%^{-}$} & \multicolumn{3}{c}{ MISO ESR $_{\%}$} \\
DATE & $1 / 2$ & $2 / 3$ & $3 / 4$ & $1 / 2$ & $2 / 3$ & $3 / 4$ \\
\hline $30 / 11 / 2007$ & 14.0 & 35.83 & 45.23 & 3.44 & 21.82 & 22.05 \\
$25 / 01 / 2008$ & 35.0 & 44.91 & 54.40 & 23.41 & 33.20 & 37.98 \\
$31 / 01 / 2008$ & 39.0 & 52.79 & 56.78 & 24.73 & 43.78 & 45.06 \\
$07 / 02 / 2008$ & 10.9 & 29.34 & 37.78 & 3.47 & 14.10 & 27.33 \\
Throughput (Mbps) & 6.03 & 8.04 & 9.05 & 6.03 & 8.04 & 9.05 \\
\hline \hline
\end{tabular}

\section{F. Comparison with literature}

Table IX shows the SISO RMS DS calculated for the COST 207 TU6 (Typical Urban) and RA (Rural Area) channel models and compares this to the RMS DS estimated in Table IV. It can be seen that the measured RMS DS is $0.24 \mu \mathrm{s}$ and falls between the TU6 and RA channel RMS DS figures [32]. The second part of Table IX compares the diversity gain measured in a simulated environment for Doppler Frequency of $1 \mathrm{~Hz}$ and $50 \mathrm{~Hz}$ in TU6 and $1 \mathrm{~Hz}$ in RA. The channel crosscorrelation is 0.25 . No data for RA frequency higher than 1 $\mathrm{Hz}$ were available at the time of writing this paper. The laboratory measurement conducted in [12] was compared with the field trials. The average maximum Doppler shift of driving tests was $20 \mathrm{~Hz}$ while the minimum and the maximum Doppler shifts were $4.4 \mathrm{~Hz}$ and $32.3 \mathrm{~Hz}$, respectively. It can be seen that the estimated diversity gain is within the expected range from 2 to $5.0 \mathrm{~dB}$ for TU6 thus validating our measured $4 \mathrm{~dB}$ of gain at $20 \mathrm{~Hz}$ for $\mathrm{ESR}_{5 \%}$.

TABLE IX

DELAY SPREAD AND TRANSMIT POWER GAIN

\begin{tabular}{|c|c|c|c|c|c|c|}
\hline \multicolumn{3}{|c|}{$\begin{array}{c}\text { SISO channel RMS DS } \\
(\mu s)\end{array}$} & \multicolumn{4}{|c|}{$\begin{array}{c}\text { Gain at } \mathrm{ESR}_{5 \%} \\
(\mathrm{~dB})\end{array}$} \\
\hline \multicolumn{2}{|c|}{ COST 207} & \multirow[b]{2}{*}{$\begin{array}{c}\text { From } \\
\text { Table } \\
\text { IV }\end{array}$} & \multicolumn{3}{|c|}{ COST 207} & $\begin{array}{l}\text { Estimated in } \\
\text { Section V.D }\end{array}$ \\
\hline TU6 & RA & & $\begin{array}{l}\text { TU6, Max } \\
\mathrm{F}_{\mathrm{D}}=1 \mathrm{~Hz}\end{array}$ & $\begin{array}{c}\text { TU6, } \\
\text { Max } \\
F_{\mathrm{D}}= \\
50 \mathrm{~Hz}\end{array}$ & $\begin{array}{c}\mathrm{RA}, \\
\mathrm{Max} \\
\mathrm{F}_{\mathrm{D}}= \\
1 \mathrm{~Hz}\end{array}$ & $\begin{array}{l}\text { Typical Max } \\
\mathrm{F}_{\mathrm{D}}=20.2 \mathrm{~Hz}\end{array}$ \\
\hline 1 & 0.1 & 0.21 & 2.0 & 5.0 & 5.2 & 4 \\
\hline
\end{tabular}

\section{G. Antenna separation}

This section presents the $\mathrm{ESR}_{\%}$ measured at different MISO antennas separations. The same set of experiments was repeated on two consecutive days, yielding near identical results and it was decided not to conduct further tests. The SISO reference set-up yielded an $\mathrm{ESR}_{\%}$ of 67.2. The MISO set-up with antennas 1-2 (e.g. $7 \lambda-\mathrm{H}), 1-3(14 \lambda-\mathrm{H})$ and 1-4 $(20 \lambda-\mathrm{H})$ yielded an $\mathrm{ESR}_{\%}$ of $58.53,54.01$, and 44.55, respectively. As expected, the MISO set-up with the largest antennas horizontal separation produced the lowest $\mathrm{ESR}_{\%}$ among the MISO test cases. According to the theoretical channel cross-correlation model presented in [4], a $20 \lambda$ antenna separation at the transmitter should be enough to achieve decorrelated diversity channels. So, it is not expected to lower the $\mathrm{ESR}_{\%}$ deploying higher antenna separations. A vertical plus horizontal antenna separation has been also tested with antennas $1-5(20 \lambda+5 \lambda)$, leading to an $\mathrm{ESR}_{\%}$ of 44.85 . The antenna at a higher position led to a higher $\mathrm{K}$ factor at the receiver, thus reducing the transmit diversity gain [11]. The results suggest that high elevation transmitter antenna would tend to reduce the diversity gain because of the increased $\mathrm{K}$ factor value.

\section{DVB-H TESTS}

In this section, a sample application to DVB-H is presented. Previous works based on software simulations present the impact of diversity at the bit error rate (BER) level (e.g. after the Viterbi decoder) [6][7] while [5] shows the DD gain taking into account also the impact of the MPE-FEC encoding. Since the implementation of MPE-FEC is not compulsory and it requires a parity overhead from $12.5 \%$ to $50 \%$ of the total bit rate, it is worthwhile to investigate in which situations the Delay Diversity can help to improve DVB-H performance without MPE-FEC. The transmitter setup is the same as the previous DVB-T investigation, except for the fact that here the DVB-H transport stream (TS) with video content is transmitted instead of PRBS. Table $\mathrm{X}$ shows the three MPE streams contained in the DVB-H transport stream and related to four different packets identification numbers (PIDs):

TABLE X

DESCRIPTION OF THE CONTENT TS ADOPTED FOR THE DVB-H TESTS.

\begin{tabular}{cccc} 
PIDs & MPE-FEC & Frame rows & Content \\
4097 & $7 / 8$ & 512 & ESG \\
4098 & $7 / 8$ & 1024 & Star Wreck Trailer \\
4099 & $7 / 8$ & 256 & Light and Life \\
\hline
\end{tabular}

In DVB-H forward error correction is defined separately for each MPE stream. In these tests we monitored the FER and the MFER of the PID 4099. The transmission parameters are summarized in Table XI.

TABLE XI

SET-UP ADOPTED FOR THE DVB-H TESTS

\begin{tabular}{ll}
\hline \hline Constellation & QPSK \\
FFT Size & $2 \mathrm{k}$ \\
Guard Interval & $1 / 32$ \\
Bandwidth & $8 \mathrm{MHz}$ \\
Code Rate & $3 / 4$ \\
Transmit Antenna Separation & $20 \lambda$ \\
\hline \hline
\end{tabular}

The DVB-H receiver can monitor one MPE stream at a time, by logging the CNR, and the DVB-H parameters every second. 


\section{A. FER\% and $M F E R_{\%}$, estimation}

Fig. 18 presents the $\mathrm{FER}_{\%}$ and $\mathrm{MFER}_{\%}$, for different values of CNR estimated along the route A. Unlike the DVB-T receiver, the DVB-H receiver does not provide the RSSI level. Attenuators rated at $0 \mathrm{~dB}, 6 \mathrm{~dB}$ and $12 \mathrm{~dB}$ were fitted to the receiver's antenna input were found to have more data at different levels of CNR. Curve points are calculated by taking into account at least 100 tables as recommended in [22] within $1 \mathrm{~dB}$ CNR interval. The curves presented in Fig. 18 show a gain of about $2.5 \mathrm{~dB}$ and $1 \mathrm{~dB}$ for $\mathrm{FER}_{5 \%}$ and $\mathrm{MFER}_{5 \%}$, respectively.

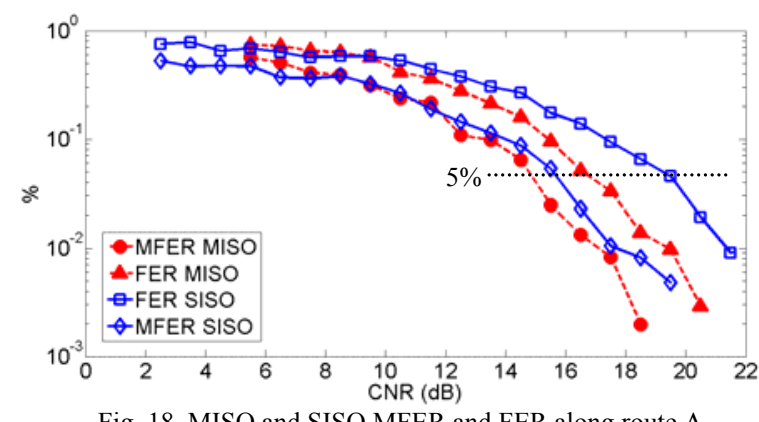

Fig. 18. MISO and SISO MFER and FER along route A

MFER $_{\%}$ is lower than $\mathrm{FER}_{\%}$ since the MPE-FEC decreases the CNR demand by $5 \mathrm{~dB}$ to $8 \mathrm{~dB}$ [31]. The DD transmit diversity gain is more obvious when the MPE-FEC is not taken into account, since this already partly exploits time diversity by introducing a virtual time-interleaving. The application of DD would have a significant impact only on the DVB-H SFN network with the MPE-FEC disabled.

\section{B. FER $\%$ and $M F E R_{\%}$, estimation along route $B$}

Tests along route $\mathrm{B}$ benefit from a more constant speed and more uniform reception environment. The time required for driving along the route B was approximately 12 minutes. Fig. 18 shows the sample means of $2 \mathrm{k}$ and $8 \mathrm{k}$ mode tests. Per each set-up, 6 test repetitions were considered. The chart also shows error bar representing the t-student 95\% CI intervals. The $8 \mathrm{k}$ set-up provides better average performances than $2 \mathrm{k}$ set-up. A possible explanation comes from the fact that $8 \mathrm{k}$ is more resistant than $2 \mathrm{k}$ to impulse noise produced by car engine ignition systems [22].

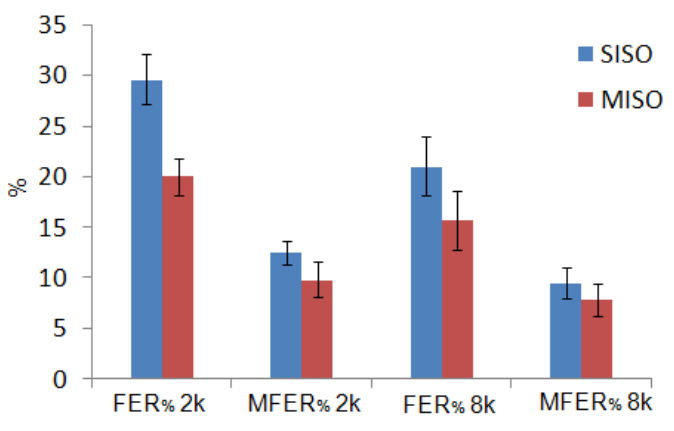

Fig. 19. FER $\%$ and MFER $\%$ sample mean along the Route B.
The $\Delta_{F E R \%}$ and the $\Delta_{M F E R \%}$ for the $2 \mathrm{k}$ are 9.7 and 2.7, respectively, while the $\Delta_{F E R \%}$ and the $\Delta_{M F E R \%}$ for the $8 \mathrm{k}$ are 5.3 and 1.7 , respectively. Also in this test case, $\Delta_{F E R \%}$ is significantly higher compared to the $\Delta_{M F E R \%}$. Although Fig. 18 shows that DD is effective also for $8 \mathrm{k}$, the performance improvements are significantly smaller compared to $2 \mathrm{k}$. In case of MFER $_{\%}$ with $8 \mathrm{k}$, the small amount of gain cannot be considered as statistically significant since the CI are almost completely overlapped.

\section{Comparison with literature}

Previous laboratory tests employing the Dibcom chipset [29] show a diversity gain in TU6 uncorrelated channel at $F_{D}=50 \mathrm{~Hz}$ for $\mathrm{FER}_{5 \%}$ and $\mathrm{MFER}_{5 \%}$ of about $3 \mathrm{~dB}$ and $1.7 \mathrm{~dB}$, respectively. These results are a good match with the $\mathrm{FER}_{5 \%}$ and MFER $_{5 \%}$ gain presented in Fig. 18. The discrepancy of about $0.5 \mathrm{~dB}$ between field trials and laboratory tests is probably due to the different test conditions.

The DVB-H FER ${ }_{5 \%}$ gain is expected to be similar with what would be achieved using the DVB-T $\mathrm{ESR}_{5 \%}$ criterion to the transport stream directly [22]. However, Fig. 18 shows a $\mathrm{FER}_{5 \%}$ gain of about $2 \mathrm{~dB}$ smaller than the $\mathrm{ESR}_{5 \%}$ gain measured in Fig. 10. It is envisaged that the gain reduction is due to the different chipset implementations, since the Dibcom receiver implements special proprietary channel estimation algorithms designed for high speed mobility resulting in enhancing of the SISO high mobility reception [21]. However, laboratory results presented in [19] shows that the $\mathrm{C} / \mathrm{N}$ threshold for MISO $\mathrm{ESR}_{5 \%}$ is the same for both Dibcom and Broadreach receivers. Thus, it can be assumed for network planning design that, when MISO diversity is applied, the $\mathrm{ESR}_{5 \%} \mathrm{C} / \mathrm{N}$ thresholds are optimal, independent of the chipset implementation and the same for all receivers.

\section{CONCLUSIONS}

DVB-T experimental results showed that, when driving in a suburban area, the number of errored seconds observed is greatly reduced and instances of acceptable reception are significantly increased. The diversity gain in terms of $\mathrm{ESR}_{5 \%}$ has been measured and found to generally agree with theoretical predictions. The coverage was improved by about $7 \%$ and $20 \%$ for the network planning reference coverage of $95 \%$ and $70 \%$, respectively. It has been shown that transmit Diversity can be used to provide a data bitrate improvement of 1 Mbps. Finally, higher gain was achieved by adopting a $20 \lambda$ horizontal separation between transmit antennas. An additional $5 \lambda$ vertical separation reduced the gain as the Ricean $\mathrm{K}$ factor figure increased. Dibcom's DVB-H experimental results shows approximately $2.5 \mathrm{~dB}$ and $1 \mathrm{~dB}$ of gain measured for $\mathrm{FER}_{5 \%}$ and $\mathrm{MFER}_{5 \%}$, respectively. The $\mathrm{FER}_{5 \%}$ gain is significantly smaller than the $\mathrm{ESR}_{5 \%}$ measured with Broadreach receiver, since the chipset implementation is already optimized for high mobility reception. The MFER $_{5 \%}$ 
gain is reduced compared to $\mathrm{FER}_{5 \%}$ because of time interleaving effects of the MPE-FEC encoding. The DVB-H gain has been also measured for 8K FFT size.

Current measurements campaigns are exploring the effectiveness of transmit diversity for indoor reception and evaluating the impact on radio network design. Resulting

\section{REFERENCES}

[1] J.-C. Guey, M.P. Fitz, M.R. Bell, W.-Y. Kuo, "Signal design for transmitter diversity wireless communication systems over Rayleigh fading channels," IEEE Trans. on Commun., vol 47 (4), pp. 527-537, Apr. 1999.

[2] S. Alamouti, "A simple transmitter diversity scheme for wireless communications," IEEE J. Select. Areas Commun., vol. 16, pp. 14511458, Oct. 1998.

[3] V. Tarokh, N. Seshadri, and A. Calderbank, "Space-time codes for high data rate wireless communications: Performance criterion and code construction," IEEE Trans. Inform. Theory, vol. 44, pp. 744-765, Mar. 1998.

[4] A. Abdi, M. Kaveh, "A space-time correlation model for multielement antenna systems in mobile fading channels," IEEE J. Selected Areas in Comm., vol. 20, no. 3, pp. 550-60, Apr. 2002.

[5] A. Dammann and S. Kaiser, "Standard conformable antenna diversity techniques for OFDM systems and its application to the DVB-T system," in Proc. IEEE Global Communication Conference, San Antonio, 2001, pp. 3100-3105

[6] Y. Zhang, J. Cosmas, M. Bard, and Y.-H. Song, "Diversity Gain for DVB-H by Using Transmitter/Receiver Cyclic Delay Diversity," IEEE Trans. On Broadcasting, vol. 52 (4), pp. 464-474, Dec. 2006.

[7] Y. Zhang, J. Cosmas, K.K. Loo, M. Bard, and R. Di Bari, "Analysis of Cyclic Delay Diversity on DVB-H Systems over Spatially Correlated Channel," IEEE Trans. On Broadcasting, vol. 53 (1), Part 2, pp. 247 255, Mar 2007.

[8] Y. Zhang, C. Zhang, J. Cosmas, K. K. Loo, T. Owens, R.Di Bari, Y. Lostanlen, and M. Bard, "Analysis of DVB-H Network Coverage With the Application of Transmit Diversity," IEEE Trans. on Broadcasting, vol. 54(3), Part 2, pp. 568-577, Sept. 2008

[9] Rohde\&Schwarz ETX-T TV Test Receiver web page product information. Available:

http://www2.rohdeschwarz.com/en/products/broadcasting/broadcasting measurement/ETX-T-|-Key Facts-|-4-|-1611.html

[10] K. Krishnapillai, H. Shirazi, J. Cosmas, M. Bard, D. Bradshow, "PLUTO Deliverable 3.2. Backwards compatibility testing," Available: http://dea.brunel.ac.uk/pluto/publications/del3-2.pdf

[11] Y. Zhang, J. Cosmas, K. K. Loo and M. Bard, "Performance Analysis of Combined CDD and Discontinuous Doppler Diversity in Rician and Rayleigh Channels," presented at the Global Mobile Congress, Shangai, Oct. 10-12, 2007.

[12] R. Di Bari, Y. Zhang, K. Nasr, J. Cosmas, K.K. Loo, R. Nilavalan, and M. Bard "Laboratory Measurement Campaign of DVB-T Signal with Transmit Delay Diversity," IEEE Trans. on Broadcasting, vol. 54, Issue 3, pp. $532-541$, Sept. 2008.

[13] R. Di Bari, M. Bard, K.M. Nasr, Y. Zhang, J. Cosmas, K.K. Loo, R. Nilavalan, H. Shirazi, K. Krishnapillai, G. Pousset, and V. Recrosio "Evaluation of Diversity Gains for DVB-T Systems," presented at the NEM 2008 Summit, Saint-Malo, France, Oct. 13-15, 2008.

[14] R. Di Bari, M. Bard, J. Cosmas, R. Nilavalan, K.K. Loo, H.Shirazi, K. Krishnapillai., "Field trials and test results of portable DVB-T systems with transmit delay diversity," presented at the IEEE Int. Symp. on Consumer Electronics, Algarve, (PO), April 14-16, 2008,

[15] R. Di Bari, M. Bard, J. Cosmas, R. Nilavalan, K.K. Loo, H. Shirazi, K. Krishnapillai., "Measurement results from transmit delay diversity for DVB-T networks," presented at the IEEE International Symposium on Broadband Multimedia Systems and Broadcasting, Las Vegas, NV, March 28-29, 2008

[16] K. Krishnapillai, R. Di Bari, H. Shirazi, J. Cosmas, M. Bard, D. Masse, M. Oksanen, C. Raynal, I. Defee, P. Kasser, "PLUTO Deliverable 3.3, Pilot Trial Facilities including Service Creation System," Available: http://dea.brunel.ac.uk/pluto/publications/del3-3.pdf
DVB broadcast networks could have fewer transmitter sites, lower EIRP or support higher data bitrates due to the increased performance and thus would be more cost-effective. Now that this technique has been shown to be viable, more complex implementations can be investigated that would further improve the effectiveness and deliver higher gains.

[17] R. Di Bari, D. Masse, M. Oksanen, M. Bard, J. Cosmas, "PLUTO Deliverable 3.4, Final Test Report," Available: http://dea.brunel.ac.uk/pluto/publications/del3-4.pdf

[18] Digital Video Broadcasting (DVB); Measurement guidelines for DVB systems, TR 101290 V1.1.1, European Telecommunications Standard Institute ETSI York, 2005

[19] R. Di Bari, Y. Zhang, K. Nasr, K. Krishnapillai, M. Bard, J. Cosmas, "PLUTO Deliverable 3.1b. Simulation Lab Facility and Test Report". Available: http://dea.brunel.ac.uk/pluto/publications/del3-1b.pdf

[20] Rappaport, Wireless Communications, Prentice Hall, 2002

[21] Dibcom product and application web page. Available: http://www.dibcom.info/Website/site/eng_accueil_applicationsproducts products chipset.htm

[22] Digital Video Broadcasting (DVB); DVB-H Implementation guidelines, TR 102377 V1.2.1. European Telecommunications Standard Institute ETSI York, Nov. 2005

[23] Digital Video Broadcasting (DVB); Transmission to Handheld Terminals (DVB-H); Validation Task Force Report, TR 102401 V1.1.1 European Telecommunications Standard Institute ETSI York, 2005

[24] H. Parviainen, P. Kyosti, X. Zhao, H. Himmanen, P.H.K. Talmola, and J. Rinne, "Novel Radio Channel Models for Evaluation of DVB-H Broadcast Systems," presented at IEEE 17th Int. Symp. on Personal, Indoor and Mobile Radio Communications, Sept. 2006.

[25] M. Abramowitz, and I.A. Stegun. Handbook of Mathematical Functions with Formulas, Graphs, and Mathematical Table. $10^{\text {th }}$ edition, Dec. 1972. Available: http://www.math.sfu.ca/ cbm/aands/intro.htm\#001

[26] ITU-R Recommendation P.1411-4 "Propagation data and prediction methods for the planning of short-range outdoor radiocommunication systems and radio local area networks in the frequency range $300 \mathrm{MHz}$ to $100 \mathrm{GHz}, 2007$

[27] W. Joseph, D. Plets, L. Verloock, E. Tanghe, L. Martens, E. Deventer, H. Gauderis, "Procedure to Optimize Coverage and Throughput for a DVB-H System Based on Field Trials", IEEE Trans. On Broadcasting, vol. 54, Issue 3, Part 1, pp. 347 - 355, Sept. 2008

[28] G. Faria, J.A. Henriksson, E. Stare, P. Talmola, "DVB-H: Digital Broadcast Services to Handheld Devices" Proceedings of the IEEE, vol. 94, Issue 1, pp. 194 - 209, Jan. 2006

[29] G. Pousset, "PLUTO Deliverable 7.2. Report on Simulated Performance Analysis. Detailed statistical analysis of performance of DVB-H Diversity Receivers in simulated test conditions," Available: on application to the authors.

[30] D. Plets, W. Joseph, L. Verloock, E. Tanghe, L. Martens, E. Deventer, and H. Gauderis, "Influence of Reception Condition, PE-FEC Rate and Modulation Scheme on Performance of DVB-H," IEEE Trans. on Broadcasting, vol. 54(3), Part 2, pp. 590-598, Sept. 2008

[31] E. MBRAI, "Specifications for Mobile and Portable DVB-T/H Radio Access," Available: http://eicta.ntc.be/index.php?id=34\&id_article=152

[32] Office for Official Publications of the European Communities, "Digital land mobile radiocommunications," Abschlussbericht, COST 207, 1989.

[33] A. Dammann, and R. Raulefs, "PLUTO Deliverable 4.1, Simulation Lab Facility and Test Report," Available: http://dea.brunel.ac.uk/pluto/publications/del4-1.pdf

[34] D. Masse, G. Pousset, "PLUTO Deliverable 7.3, Report on Dibcom Rx Pilot Trial Performance Analysis, "Avilable: on application to the authors. 